
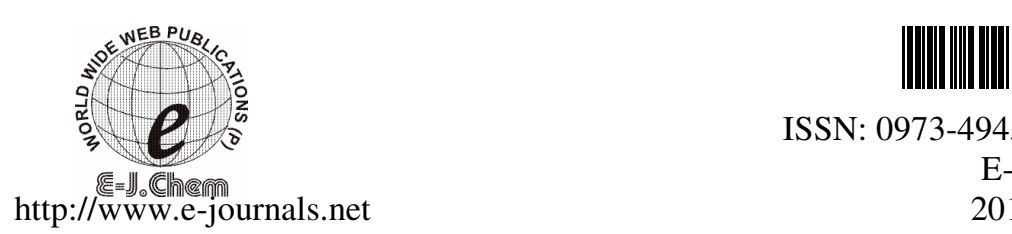

ISSN: 0973-4945; CODEN ECJHAO

E-Journal of Chemistry 2010, 7(S1), S169-S174

\title{
Estimation of Heavy Metals in Multivitamin Tablets by Differential Pulse Anodic Stripping Voltammetry
}

\author{
KUMAR ROHIT RAJ*, SHASHANK SHARMA ${ }^{\S}$, SACHIN SAXENA $^{\S}$, \\ M.M. SRIVASTAVA and SOAMI P. SATSANGI ${ }^{\S}$ \\ Department of Chemistry, Faculty of Science \\ Dayalbagh Educational Institute, Agra-282110, India \\ ${ }^{\S}$ USIC, Dayalbagh Educational Institute, Agra-282110, India \\ rohitraj.rj@gmail.com
}

Received 9 March 2010; Accepted 3 May 2010

\begin{abstract}
Differential pulse anodic stripping voltammetry (DPASV) was applied for the simultaneous determination of zinc and copper in multivitamin tablet (supradyn and centrum). Determination of the metals was made in ammonium acetate buffer $(\mathrm{pH} 4.5)$ with a scan rate of $0.01 \mathrm{~V} / \mathrm{s}$ by Hanging Mercury Dropping Electrode (HMDE). The solution was stirred during electrolysis at $-1.3 \mathrm{~V}$ for $300 \mathrm{~s}$ in the potential range of -1.3 to $+0.1 \mathrm{~V}$. Concentrations of zinc and copper in supradyn drug sample were found to be 1.80 and $2.9 \mathrm{mg} /$ tablet and for centrum drug sample were found to be 4.6 and $0.94 \mathrm{mg} /$ tablet respectively.
\end{abstract}

Keywords: Multivitamin, DPASV, Hg electrode, HMDE.

\section{Introduction}

Multivitamin tablets are very popular and widely used in our country and abroad. They contain, in general, essential vitamins (C and E) and some other trace elements. As medicines, these are good alternative of the natural source of the vitamins and minerals, having no any side effects ${ }^{1}$. Trace elements are a good supplement to maintain the health and to combat the stress and fatigue due to constant work load, but in excess dose they become toxic. Excess $\mathrm{Zn}$ may result in chronic metabolic disturbances and retardation of growth $^{2}$. If present in high concentration in the soil and or plant, it will interfere with the normal $\mathrm{Fe}$ metabolism in the plants, resulting in typical iron deficiency symptoms ${ }^{3}$. An excess of copper will induce chlorosis and Fe deficiency ${ }^{3}$. With high awareness of the toxic effects of heavy metal ions on human, animal, plant and aquatic life, detection of these metal ions has become a global problem ${ }^{4}$. 
Analytical methods for quantitative determination of multivitamin tablets are based on high performance liquid chromatography combined with either mass spectrometry ${ }^{5-7}$ or fluorescence detection ${ }^{8}$, on gas chromatography ${ }^{9}$, capillary electrophoresis ${ }^{10}$ and UV spectroscopy ${ }^{11}$.

Pharmaceutical compounds including multivitamin contain various electro active groups which can be readily measurable by electrochemical detections. Electro analytical techniques have many advantages as measurement systems. In recent years voltammetry has witnessed a renaissance with regard to its applications in determination of trace metals and organic substances in a wide dynamic range from ppm to ppb levels. The benefits of voltammetric techniques compared to other analytical techniques are its high sensitivity, ease of minimum sample pretreatment prior to analysis, high accuracy, in multi element analysis simultaneously and its application in speciation studies ${ }^{12,13}$. Electrochemical stripping analysis has long been recognized as a powerful technique for detection of traces of heavy metals in drug samples ${ }^{14}$. Its remarkable sensitivity is attributed to the combination of an effective pre concentration step with pulse measurement techniques that generate an extremely high signal-to-background ratio.

The present paper describes electrochemical characterization of some commercially available multi vitamin tablets for trace metals like $\mathrm{Zn}$ and $\mathrm{Cu}$ using differential pulse stripping voltammetry. The process has been optimized considering various sectors like $\mathrm{pH}$, purging time, deposition potential and deposition time.

\section{Experimental}

Measurements were done using the Eco Chemie-make potentiostat/galvanostat AUTOLAB$302 \mathrm{~N}$, using GPES software. Differential pulse anodic stripping voltammetry was performed with a three electrodes system, in conjunction with the IME 663. HMDE was used with an $\mathrm{Ag} / \mathrm{AgCl}$ reference electrode and platinum as an auxiliary electrode.

\section{Chemicals and reagents}

Commercially available multivitamin tablets (supradyn and centrum) were obtained. The standards of zinc nitrate, cupric nitrate, liquid ammonia, potassium chloride and acids solution were used of analytical grade purchased from E-Merck. Standard solutions of $\mathrm{Cu}$ and $\mathrm{Zn}$ were prepared by appropriate dilution of stock solution with deionized water. To transfer all the standard solutions to the electrolyte, micropipettes with disposable tips were used. Glassware used were washed properly with $\mathrm{HNO}_{3}$ acid and rinsed with deionized water.

\section{Preparation of standards and working electrolyte}

Stock solutions of $\mathrm{Cu} \& \mathrm{Zn}(500 \mathrm{ppm})$ were prepared with individual pure nitrates by diluting with deionised water. The standard solutions of different concentrations $(1,2,3$ and $4 \mathrm{ppm}$ ) was prepared daily with stock solution for calibration. Ammonium acetate buffer ( $\mathrm{pH} 4.5$ ) was prepared by mixing $7.7 \mathrm{~g}$ ammonia and $1 \mathrm{~mL}$ acetic acid in $100 \mathrm{~mL}$ volumetric flask. The solution was made up to the mark with deionised water.

\section{Sample preparation}

The outer coatings of the multivitamin tablets, considered for the study was removed by washing it with deionised water and then it was dried in oven at $120{ }^{\circ} \mathrm{C}$ for one hour. Crushed the tablets thoroughly in a mortar and pestle to make it fine powder. Dried powdered sample $(1 \mathrm{~g})$ of each was taken in a $100 \mathrm{~mL}$ conical flask separately with conc. $\mathrm{HNO}_{3}(5 \mathrm{~mL})$ and stand it overnight for predigestion. Aquaregia $(5 \mathrm{~mL})$ was added to it and 
placed on a hot plate for $2 \mathrm{~h}$. Solution was heated till it becomes clear. The solution was then cooled and filtered with Whatman paper no. 42 and diluted up to $100 \mathrm{~mL}$ with deionised water.

\section{Procedure}

Electrode used for the analysis was cleaned (washed gently with sulphuric acid and deionised water). The three electrode systems were adjusted $(\mathrm{Ag} / \mathrm{AgCl}$ as reference electrode, platinum as auxiliary electrode and mercury as working electrode). For the analysis, $20 \mathrm{~mL}$ of deionised water, $3 \mathrm{~mL}$ of ammonium acetate buffer as supporting electrolyte and $1 \mathrm{~mL}$ of acid digested sample was taken in the mercury pool. For increasing the conductivity of the solution, $1 \mathrm{~mL}$ $\mathrm{KCl}(3 \mathrm{M})$ was added to it. Differential pulse anodic stripping voltammetry has been carried out with HMDE at a given parameters (Purge Time: $120 \mathrm{sec}$; Conditioning Time: $5 \mathrm{sec}$; Deposition Potential: -1.3V; Deposition Time: $300 \mathrm{sec}$; Initial Potential: -1.3 V; End Potential: $0.1 \mathrm{~V}$; Step Potential: $0.005 \mathrm{~V}$; Modulation Amplitude: 0.025; Modulation Time: 0.05s and Scan Rate: $0.01 \mathrm{~V} / \mathrm{s})$. All the experiments have been conducted in five replicates.

\section{Results and Discussion}

\section{Effect of strong acids and purge time}

In trace analysis experiments, organic complexants provide one of the serious interference factors, as most of the organic compounds have the reducible or oxidizable moieties, which are electrochemically active at the mercury electrode and form metal-ligand complexes. For this purpose, drug sample was digested properly by acid solutions to suppress the organic matrices and to separate the free metal ions. The presence of oxygen also interferes with such a system, so the solution was purged with nitrogen gas and the solution was blanketed with a stream of nitrogen gas.

\section{Effect of $p H$}

The peak shape changed with the change in $\mathrm{pH}$. At higher $\mathrm{pH}$, the peak height fell and the peak current for $\mathrm{Cu}$ reduced drastically. However with $\mathrm{Cu}$ and $\mathrm{Pb}$, increasing the acidity enhances the ASV peak size and peaks tend to be sharper, which leads to a greater sensitivity for the determination of $\mathrm{Cu}$. It has been postulated that $\mathrm{Cu}$ forms a series of compounds of general formula $\mathrm{Cu}_{n}(\mathrm{OH}) 2 n-2\left(\mathrm{H}_{2} \mathrm{O}\right)_{4}$, where $n$ increases with $\mathrm{pH}$. At $\mathrm{pH}$ values lower than 3.8, the peak current of $\mathrm{Zn}$ decreases and broadening of peaks took place at $\mathrm{pH}$ values higher than 5.0. Therefore, the $\mathrm{pH}$ was optimized at 4.5 for the study.

\section{Effect of deposition potential}

The variation of deposition potentials on the stripping currents of various metal ions was studied. Potentials more negative than $-1.40 \mathrm{~V}$ cause hydrogen evolution, which affected the peak currents. The mercury droplets were distorted by the evolved hydrogen, which leads to increased base currents, which in turn has direct consequences on the reproducibility. The potential more positive than $-1.30 \mathrm{~V}$ affected the stripping peak of $\mathrm{Zn}$. Therefore, an optimum potential of $-1.30 \mathrm{~V}$ was selected as a suitable accumulation potential for the study, as this allows the relevant elements to be deposited.

\section{Effect of deposition time}

The influence of accumulation time on the peak current was studied in the range $60-300 \mathrm{sec}$ at $\mathrm{pH} 4.5$ and at a deposition potential of $-1.30 \mathrm{~V}$. At higher accumulation time, decrease in peak current of $\mathrm{Zn}$ and $\mathrm{Cu}$ were observed in the concentration range taken for 
the present analysis. This may be due to the formation of inter-metallic compounds of these metals. Deposition time less than $300 \mathrm{sec}$ affects the determination of $\mathrm{Zn}$ in the drug samples. Therefore, the accumulation time was optimized at $300 \mathrm{sec}$.

\section{Analysis of peaks}

Typical differential pulse anodic stripping voltammograms were obtained for the determination of trace metals in drug tablets. Two peaks were found in the selected potential range of $-1.3 \mathrm{~V}$ to $+0.1 \mathrm{~V}$. The peaks at $-1.18 \mathrm{~V}$ and $-0.04 \mathrm{~V}$ correspond to $\mathrm{Zn}$ and $\mathrm{Cu}$ respectively. Different concentrations of standard were run at the same parameters. All the elements in unknown samples were determined by standard addition method. The voltammogram of two samples were recorded separately as shown in Figure 1 (a) and (b).

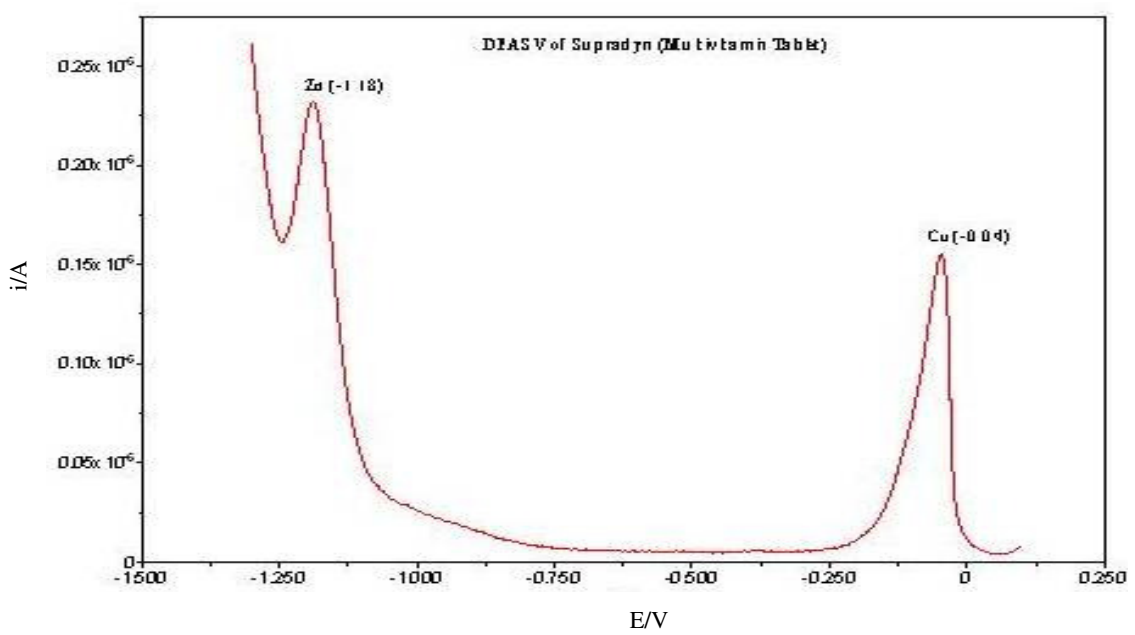

Figure 1(a). DPASV of supradyn tablet.



Figure 1(b). DPASV of centrum tablet.

A peak height corresponding to different concentration of the standard was measured and calibration curve was plotted with concentration on the $\mathrm{x}$-axis and peak height on the y-axis, as shown in Figure 2 (a) and (b). 

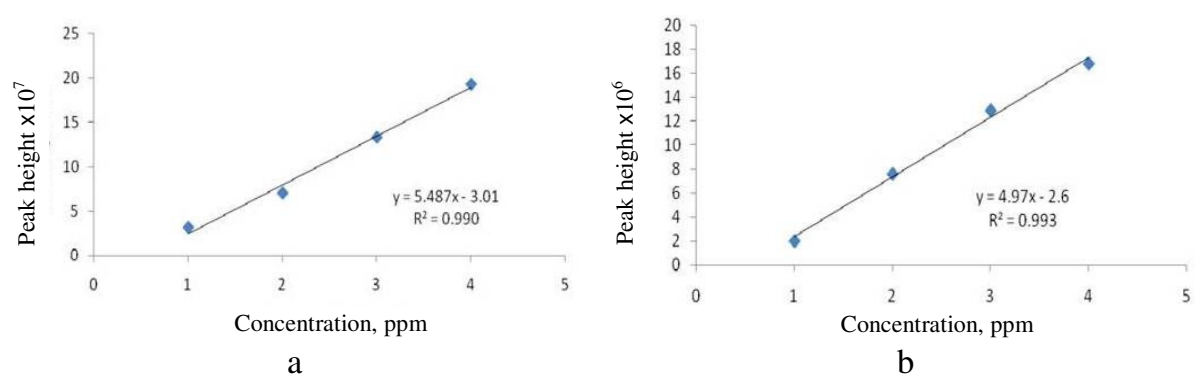

Figure 2(a) \& (b). Calibration curve of standards of $\mathrm{Zn}$ and $\mathrm{Cu}$

The data points of all the samples were fitted well with the straight line. A good correlation coefficient 0.990 and 0.993 were obtained for $\mathrm{Zn}$ and $\mathrm{Cu}$ respectively. The regression equation for $\mathrm{Zn}$ and $\mathrm{Cu}$ was found to be $\mathrm{Y}=5.487 \mathrm{x}-3.01$ and $\mathrm{Y}=4.97 \mathrm{x}-2.6$ respectively. On the basis of calibration curve of standard, concentration of $\mathrm{Zn}$ and $\mathrm{Cu}$ in multivitamin tablets supradyn: 1.80 and $2.9 \mathrm{mg} /$ tablet and centrum: 4.6 and $0.94 \mathrm{mg} / \mathrm{tablet}$ respectively. Our results on the estimation of $\mathrm{Zn}$ and $\mathrm{Cu}$ in the target multivitamin tablets were found to be in close proximity of the reported values (Table 1).

Table 1. Concentration of metals present in multivitamin tablets.

\begin{tabular}{cccc}
\hline Metals & Peak position & $\begin{array}{c}\text { Concentration }(\text { mean } \pm \text { SD), } \\
\text { mg/tablet Obtained }\end{array}$ & $\begin{array}{c}\text { Concentration, } \\
\text { mg/tablet Reported }\end{array}$ \\
\hline & & Supradyn & \\
$\mathrm{Zn}$ & $-1.18 \mathrm{~V}$ & $1.80 \pm 0.5$ & 2.20 \\
$\mathrm{Cu}$ & $-0.04 \mathrm{~V}$ & $2.95 \pm 0.3$ & 3.39 \\
& & Centrum & 5.00 \\
$\mathrm{Zn}$ & $-1.20 \mathrm{~V}$ & $4.60 \pm 0.2$ & 1.00 \\
$\mathrm{Cu}$ & $-0.06 \mathrm{~V}$ & $0.94 \pm 0.5$ & \\
\hline
\end{tabular}

\section{Conclusion}

Differential pulse anodic stripping voltammetry thus provides good sensitivity, low background currents (interference) and good stability in HMDE. The results and observations have revealed that the use of $\mathrm{Hg}$ as a working electrode is very sensitive and give precise results. In multivitamin drug samples, $\mathrm{Zn}$ and $\mathrm{Cu}$ are present in the trace amounts and within permissible limits. It was confirmed by the appearance of peaks of standard and sample at $-1.18 \mathrm{~V}$ and $-0.04 \mathrm{~V}$ in voltammogram, corresponding to $\mathrm{Zn}$ and $\mathrm{Cu}$ respectively. The concentration of $\mathrm{Zn}$ and $\mathrm{Cu}$ were found in multivitamin tablets supradyn: 1.80 and $2.9 \mathrm{mg} /$ tablet and centrum: 4.6 and $0.94 \mathrm{mg} / \mathrm{tablet}$ respectively. The proposed electro analytical method for the analysis of metals in drug sample is portable, easily renewable and relatively inexpensive method as compared to the other analytical techniques.

\section{Acknowledgment}

Authors gratefully acknowledge Prof. V.G. Dass, Director, Dayalbagh Educational Institute and Prof. L.D. Khemani, Head, Department of Chemistry, Dayalbagh Educational Institute, for providing necessary facilities for the research. Authors also acknowledge Ministry of Human Resource Development, Govt. of India, for rendering financial assistance under NMEICT project. 


\section{References}

1. Ali Z, Abu Zuhri and Wolfgang Voelter, Fresenius J Anal Chem., 1998, 360, 1-9.

2. Sayama N, Yoshida Y, Mori K, Fukazawa H, Hori H, Nakazato M, Tani J I., Nakagawa Y and Ito S, Endocr J [Tokyo], 1998, 45, 767.

3. Jones J. B., "Plant Nutrition Manual". 1998, CRC Press, LLC, Boca Raton, Florida.

4. Ronald J Mascarenhas, Ashis K Satpati, Shivaraj Yellappa, Bailure S Sherigara and Ajjikuttira K Bopiah, Anal Sci., 2006, 22(6), 871-875

5. Yang AY, Sun L, Muson DG and Zhao J J, J Pharm Biomed Anal., 2005, 38(3), 521-527.

6. Miao X S and Metcalfe C D, J Chromatogr A., 2003, 998, 133-141.

7. Yang H, Feng Y and Luan Y, J Chromatogr B., 2003, 785, 369-375.

8. Ochiai H, Uchiyama N, Imagaki K, Hatta S and Kamei T, J Chromatogr B: Biomed Sci Appl., 1997, 694(1), 211-217.

9. $\quad$ Erturk S, Onal A and Cetin S M, J Chromatogr B., 2003, 793, 193.

10. Srinivasu M K, Raju A N and Reddy G O, J Pharm Biomed Anal., 2002, 29, 715-721.

11. Wang L and Asgharnejad M, J Pharm Biomed Anal., 2000, 21, 1243.

12. Jain C K and Ali I, Water Res., 2000, 34(17), 4304-3412.

13. Zuman P, Anal Lett., 2000, 33, 163.

14. Taillefert M, Luther III G W and Nuzzio D B, Electroanalysis, 2000, 12(6), 401-412. 


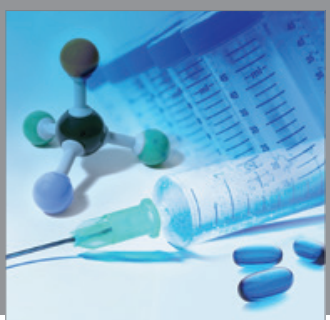

International Journal of

Medicinal Chemistry

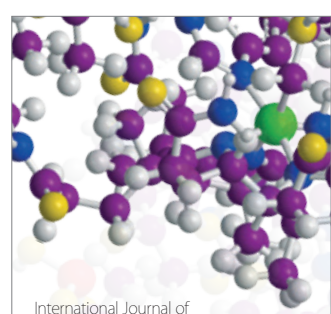

Carbohydrate Chemistry

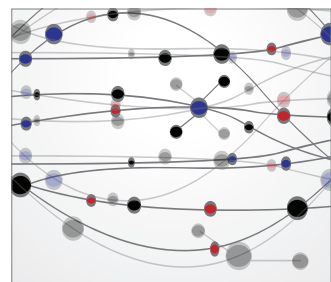

The Scientific World Journal
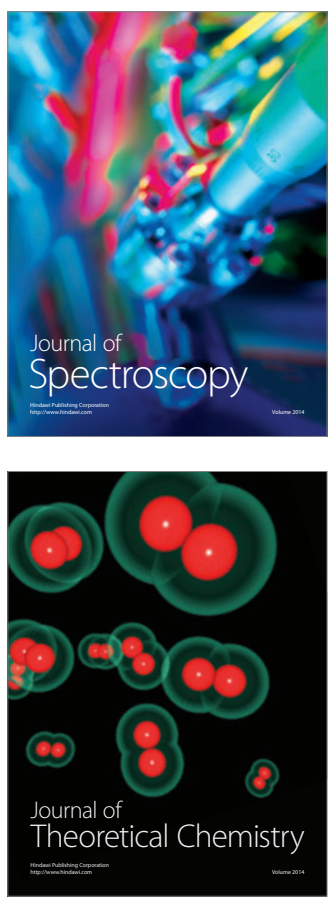
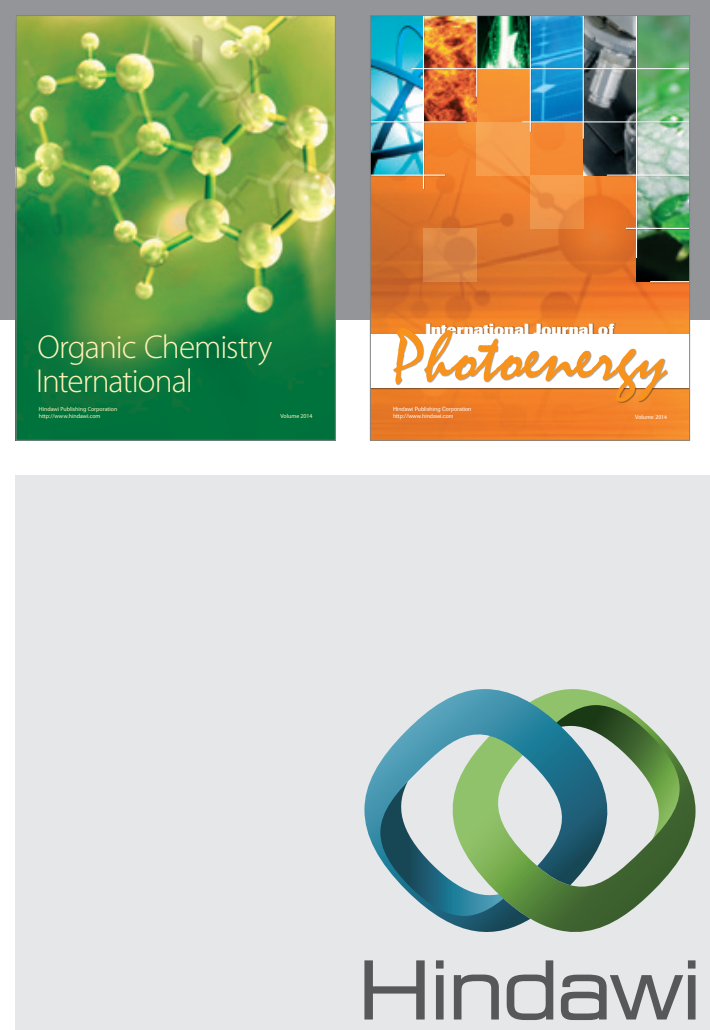

Submit your manuscripts at

http://www.hindawi.com



Journal of

Applied Chemistry
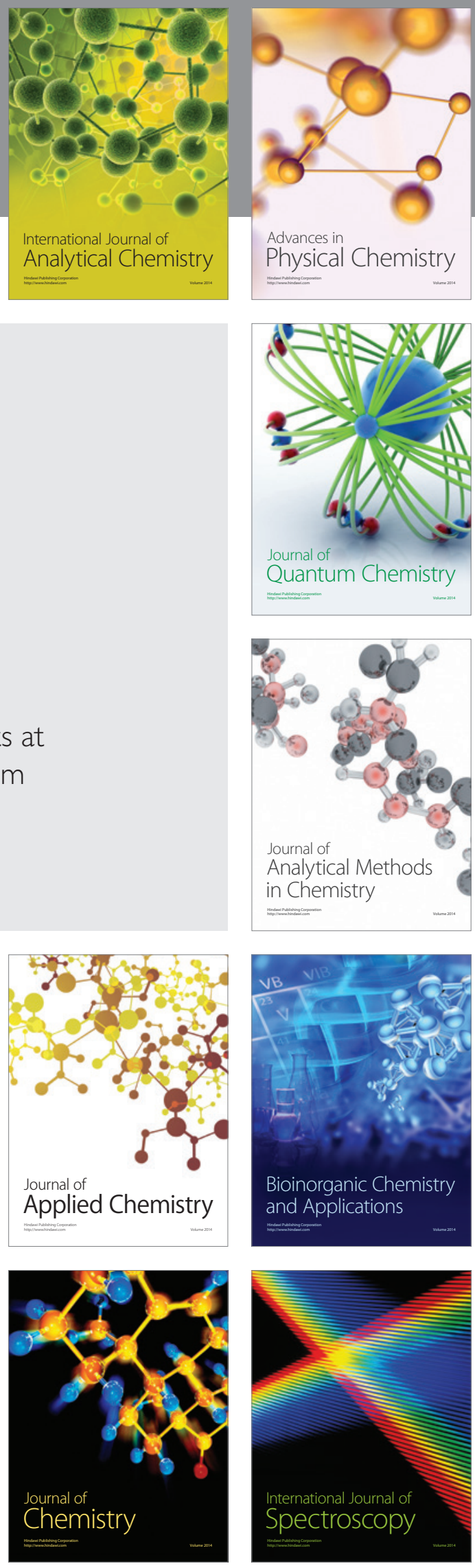